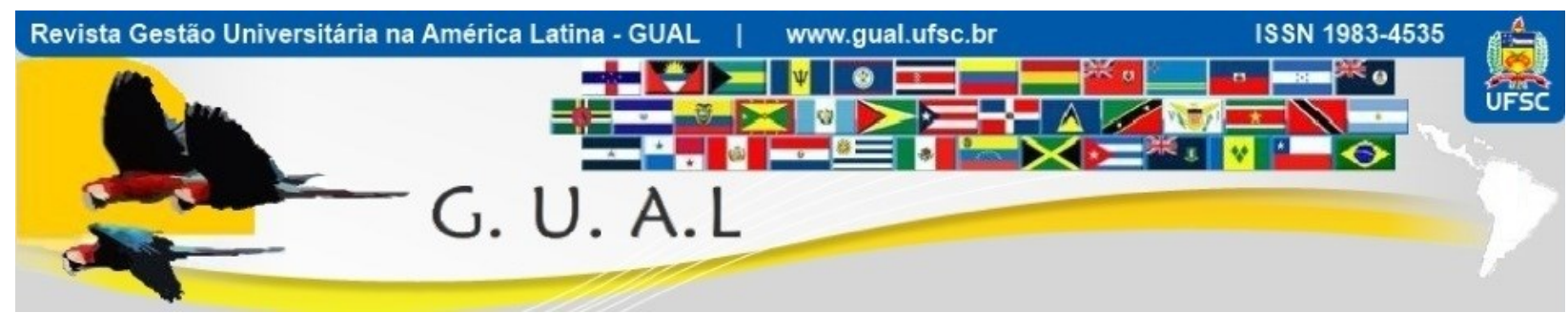

DOI: http://dx.doi.org/10.5007/1983-4535.2015v8n1p298

\title{
EGRESSOS COMO INSTRUMENTO DE AVALIAÇÃO INSTITUCIONAL: UMA ANÁLISE DA FORMAÇÃO E EMPREGABILIDADE DOS EGRESSOS DA FEA-RP/USP
}

\section{THE GRADUATE AS A TOOL OF INSTITUTIONAL ASSESSMENT: AN ANALYSIS OF ACADEMIC KNOWLEDGE AND EMPLOYABILITY WITH FEARP/USP GRADUATES}

Claudio de Souza Miranda, Doutor Universidade de São Paulo - USP csmiranda@,fearp.usp.br

Elaine Toldo Pazello, Doutora Universidade de São Paulo - USP epazello@usp.br

Cristina Bernardi Lima, Especialista Universidade de São Paulo - USP cebelima@usp.br

Recebido em 05/maio/2014

Aprovado em 25/novembro/2014

Sistema de Avaliação: Double Blind Review Esta obra está sob uma Licença Creative Commons Atribuição-Uso. 


\title{
RESUMO
}

O processo de avaliação na educação tem sido foco de diversos estudos, inclusive no ensino superior. O processo de avaliação pode ocorrer em diversos momentos da formação e entre estes está a avaliação de egressos. O foco deste estudo foi a Faculdade de Economia, Administração e Contabilidade da USP de Ribeirão Preto com o objetivo de responder a seguinte pergunta: como se caracteriza a inserção dos alunos egressos no mercado de trabalho? A faculdade tinha 17 turmas formadas com 1520 egressos de seus três cursos dos quais se obteve contato de 1185, e destes obteve-se 725 respostas. A maior parte dos egressos está na região Sudeste, principalmente em São Paulo $(84,7 \%)$. Em termos de formação complementar observa-se que $32,1 \%$ fizeram especialização e $28,1 \%$ fizeram mestrado. Em relação à empregabilidade observou-se 91,8\% empregados, 5,0\% procurando emprego e apenas 3,2\% inativos. Entre os empregados, 80,9\% alegaram estar atuando em sua área de formação. As principais formas de atuação são de empregados na iniciativa privada e no setor público, com renda média de $\mathrm{R} \$ 9.6313$. Em relação à sua formação, indicaram uma nota média de 8,2 apesar de fazerem algumas críticas em relação a um afastamento dos docentes da realidade do mercado.

Palavras-chave: Avaliação de Egressos. Mercado de Trabalho. Ensino Superior.

\begin{abstract}
The assessment process in education has been the target of many studies, including higher education. The assessment process can occur during several levels; this study is done with the graduates. The focus of this study was the Faculty of Economics, Business and Accouting of Ribeirão Preto - USP, in order to answer the following research question: How is the integration of graduate students in the market? The faculty had 17 graduate groups that was composed of 1,520 graduates in its three courses. The researchers were able to connect 1,185, and they obtained 725 answers. Most of the graduates are in the Southeast, especially in São Paulo (84.7\%). In terms of post-graduation courses, $32.1 \%$ were at MBA courses and $28.1 \%$ were at Mastering courses. Regarding employability was observed $91.8 \%$ are employed, $5.0 \%$ are looking for jobs and only 3.2\% are inactive. Among the employed, $80.9 \%$ acts at their graduation area. These employees are at public and private sector, and they have an average income of $\mathrm{R} \$ 9,6313$. About the graduation course they scored 8.2 out of 10 , despite some criticism of undergraduate learning and the market.
\end{abstract}

Keywords: Job Market. Alumni evaluation. Higher Education. 


\section{INTRODUÇÃO}

Processos de avaliação são uma constante na sociedade em que hoje vivemos. Este processo pode ter diversos objetivos como fornecer diagnósticos, verificar a execução de tarefas, monitorar progressos entre outros. Sua aplicação pode se desenvolver em diversas áreas, entre elas a área educacional, buscando avaliar tanto aspectos específicos de cada aluno, como também de uma instituição de ensino e até mesmo da política educacional adotada por um governo.

Sobrinho (2010) expõe que a avaliação é a ferramenta principal para a organização e implementação das reformas educacionais. Ela permite o desenvolvimento de mudanças nos currículos, nas metodologias de ensino, nos conceitos e práticas de formação, na gestão, nas configurações do sistema educativo, nas políticas e prioridades da pesquisa, nas noções de pertinência e responsabilidade social. Ribeiro (2011) complementa que os processos de avaliação no ensino superior são políticas públicas com grande capacidade para promover mudanças e adequações nos sistemas de ensino frente às demandas sociais.

O processo de avaliação na Universidade de São Paulo (USP) é desenvolvido a partir de diversas bases, principalmente pelo tripé do ensino, pesquisa e extensão. Este processo é desenvolvido tanto de forma centralizada, por meio da Reitoria, como de forma descentralizada quando realizado por cada uma de suas unidades de ensino. O processo de avaliação do ensino é desenvolvido de forma contínua, tanto centralmente quanto isoladamente, porém a avaliação de seus egressos raramente foi foco central de avaliação.

Porém, no segundo semestre de 2012, a USP lançou seu programa de acompanhamento de egressos para avaliar a atividade profissional de seus 400 mil egressos de graduação e pós-graduação. A USP entende que os resultados obtidos representam parâmetros relevantes para avaliar a qualidade do ensino e da formação oferecidos por ela, e para o constante aperfeiçoamento dessas atividades para os futuros ingressantes. A avaliação institucional na USP é coordenada pela Comissão Permanente de Avaliação (CPA), a quem compete propor, ao Conselho Universitário (Co), diretrizes para essa finalidade, bem como fornecer a ele e ao Reitor análises qualitativas e quantitativas sobre o desempenho da Universidade, no que se refere às atividades-fim.

Atuando de forma antecipada à Universidade, a FEARP/USP, em seu planejamento estratégico, observou a importância do processo de acompanhamento de seus egressos, como 
forma de melhorar suas atividades de graduação e pós-graduação e, ainda no primeiro semestre de 2012, fez uma primeira coleta de dados junto seus egressos.

A unidade contava à época (no momento do desenvolvimento do projeto) com 17 turmas formadas dos cursos de Administração, Ciências Contábeis e Ciências Econômicas. Contabilizavam-se ao período em análise 2266 ingressantes, sendo que 1520 tinham concluído sua formação. A pesquisa desenvolvida buscou responder ao seguinte questionamento: como se caracteriza a inserção dos alunos egressos no mercado de trabalho? Perguntas específicas a esse objetivo mais geral são: qual a porcentagem de egressos presentes no mercado de trabalho? Qual a porcentagem que trabalha em ocupações relacionadas à sua formação? Quantos prosseguiram os estudos em programas de pósgraduação? Qual o salário médio recebido pelos egressos? Qual sua percepção sobre sua formação?

Neste artigo apresentam-se os resultados dessa coleta de dados junto aos egressos. O conhecimento da situação dos egressos, bem como a avaliação de sua formação, podem oportunizar melhorias na qualidade de ensino, de seus conteúdos e na comunicação com egressos. Essas informações podem ainda motivar os alunos atuais, bem como futuros ingressantes com a construção de uma imagem positiva da IES. Os resultados também são importantes para a IES e para os demandantes de ensino superior de uma forma geral, na medida em que a qualidade da inserção do egresso no mercado de trabalho pode ser vista como uma variável correlacionada com a qualidade da formação desse egresso.

\section{REVISÃO DE LITERATURA}

O bloco a seguir busca apresentar apontamentos gerais sobre o processo de avaliação de egressos, e apresenta alguns trabalhos anteriores, aplicados a cursos da área de negócios, sobre acompanhamento de egressos, que serviram de referência para o desenvolvimento deste trabalho.

\subsection{O PROCESSO DE AVALIAÇÃO DE EGRESSOS}

A qualidade da educação é um tema amplamente discutido na nossa sociedade, desde a educação de base até a superior. Segundo Stadtlober (2010) na educação superior a avaliação da qualidade é utilizada pelo Estado como principal critério para avaliar as Instituições de Ensino Superior (IES) e os cursos superiores, bem como a sociedade de forma geral também 
avalia os cursos por suas notas e resultados.

Abreu Júnior (2009) aponta que o mundo acadêmico adota, prioritariamente, indicadores e critérios quantitativos para a qualidade da educação, entre eles o número de professores doutores e o número de publicação em revistas indexadas. A sociedade, por sua vez, parece considerar a qualidade diretamente atrelada a fatores como concorrência nos processos de admissão, empregabilidade e o sucesso profissional de seus egressos, reputação do quadro docente e suntuosidade das instalações.

A partir de 2004, com o propósito de alargar as fronteiras da avaliação educacional, o MEC instituiu o Sistema Nacional de Avaliação da Educação Superior (SINAES). Esse sistema contempla de forma integrada a avaliação da instituição, dos cursos e do desempenho dos estudantes, permitindo assim que a própria IES verifique sua qualidade e sua responsabilidade social.

Uma das dimensões analisadas pelo SINAES refere-se à política de atendimento a estudantes e egressos. E, dessa forma, há orientações para que a IES faça avaliações da inserção profissional de seus egressos e a participação deles na vida da instituição.

Coelho e Oliveira (2012) apontam que os egressos podem exercer a função de permuta no diálogo da Universidade com a Sociedade na medida em que poderão trazer informações para o interior dos colegiados dos cursos. Os autores ainda indicam que a preocupação do governo brasileiro com o acompanhamento de egressos foi tardia, mas ainda assim, louvável.

Coelho e Oliveira (2012) também assinalam que em Países da União Européia é prática cotidiana manter processos avaliativos com diplomados, envolvendo familiares e empregadores destes, visando modificações ou ajuste nos conteúdos curriculares e sua articulação com outros setores, em especial o do emprego. Os autores indicam que em Portugal este acompanhamento tem gerado diversos estudos principalmente para reflexões sobre o papel social da Universidade.

Apesar de a avaliação de egressos ser uma das avaliações incluídas no SINAES, Meira e Kurcgnant (2009), em revisão de literatura efetuada, apontam que foram encontradas poucas referências que evidenciam a percepção de egressos como indicador de avaliação institucional. As autoras apontam que os estudos realizados buscam aprender os aspectos considerados importantes, pelo egresso, no seu processo formativo.

Michelan et al (2009) desenvolveram um levantamento extenso sobre egressos, e a partir das informações levantadas chegou-se às possibilidades e às potencialidades de gestão 
de egressos em quatro diferentes níveis de intensidade de interação da IES com o Egresso: Registro e Acompanhamento do Perfil do Egresso; Avaliação da IES e do Curso pelo Egresso; Fatores de Dificuldade e Facilidade de Inserção do Egresso no Mercado; e Relacionamento com o Egresso.

Para o primeiro nível de registro e acompanhamento, foco deste trabalho, Michelan et al (2009) apontam que são importantes quatro níveis de levantamentos: a) Registro pessoal e sócio-econômico; b) Informações relacionadas à formação acadêmica no ensino, pesquisa e extensão; c) Aceitação do egresso no mercado; e d) Histórico profissional.

Lousada e Martins (2005) buscaram explicar a relação entre a qualidade da gestão do ensino e a importância de sistemas de acompanhamento de egressos. Para tanto, fizeram uma avaliação das percepções e motivações de 19 dirigentes de nove universidades dos estados de São Paulo e Santa Catarina, com foco principal para cursos de Ciências Contábeis.

As entrevistas desenvolvidas por Lousada e Martins (2005) demonstram que nem sempre as IES estão preparadas para o desenvolvimento das pesquisas nem a utilização dos dados que elas geram. Ao se avaliar a capacitação prática de seus egressos, alguns dirigentes entrevistados, indicam que o que falta, ainda, para os alunos é o desenvolvimento de conteúdos de enfoque prático. Apesar de a maioria das Instituições trabalharem com laboratórios, as simulações existentes, ainda, não são suficientes para atingir a qualificação necessária. Os autores ainda indicam que apenas uma IES usou o resultado da pesquisa como uma das bases para revisão do seu projeto político pedagógico (PPP) do curso.

\subsection{ESTUDOS ANTERIORES SOBRE EGRESSOS NA ÁREA DE NEGÓCIOS}

Apresentam-se a seguir alguns dos trabalhos prévios estudados com enfoque em cursos da área de negócios. Cabe ressaltar que nesta área poucos trabalhos foram localizados, mas isso é frequente também em outras áreas como engenharia e saúde.

Stadtlober (2010) analisou como os egressos do curso de Administração de uma IES privada avaliam a qualidade do seu curso de graduação em relação à qualificação na profissão de administrador. Os egressos avaliaram que se sentiam satisfeitos com a formação que tiveram, mas tinham consciência que, para serem bons profissionais e gerarem impacto social, teriam que, cada vez mais se qualificar.

Stadtlober (2010) aponta que a satisfação com o trabalho foi avaliada em vários aspectos e chegou à conclusão que somente uma avaliação objetiva não abrange todas as 
questões que englobam este item. Há muitos ângulos, com múltiplas subjetividades para avaliar a satisfação e os aspectos que motivam cada pessoa para o desenvolvimento da atividade profissional.

Brandalise et al (2013) fizeram levantamento de egressos do curso de Administração da Unioeste (Cascavel-PR), que já tem mais de 30 turmas formadas, conseguindo uma amostra de 308 estudantes que representava 27,6\% de seus egressos. Seu objetivo foi demonstrar o papel social da universidade no preparo profissional de seus egressos. Para tanto avaliou, entre outros, sua educação continuada, seu domínio de outros idiomas, sua empregabilidade em termos de forma de atuação e do ramo de atuação.

Além disso, a pesquisa de Brandalise et al (2013) avaliou a renda dos egressos comparando a mesma antes da formação e no momento da pesquisa. A pesquisa, porém não faz análises comparativas das características levantadas em termos de tempo de formação do egresso.

Meireles et al (2013) desenvolveram um levantamento com 115 egressos do curso de Administração da Universidade Federal do Ceará (UFC), formados entre 2002 e 2011, com outra abordagem que buscava avaliar a importância dos temas tratados para formação do administrador, o grau de absorção de 27 áreas de conhecimentos adquiridos pelo egresso de Administração no seu curso acerca dos temas expostos e a utilização dos conhecimentos tratados.

Meireles et al (2013) apontam que os resultados encontrados no estudo podem ajudar a melhorar a grade curricular do curso de Administração, pois refletem a percepção dos egressos do curso que em sua maioria já estão no mercado de trabalho. Porém, os dados apresentados no estudo não apontam diferenças de percepção em termos de tempo de formação e área de atuação.

Puges (2008) avaliou 448 egressos, de cursos de Ciências Contábeis do estado do Rio Grande do Sul, que fizeram seu registro profissional no conselho de classe entre 1996 e 2005, o que representou 5,8\% dos profissionais registrados, gerando uma amostra não probabilística. As principais áreas de atuação foram as de controladoria (16,3\%) e contabilidade societária $(13,2 \%)$, cabe ressaltar que 12,5\% alegaram não atuar na área contábil, e $67 \%$ já atuavam na área contábil antes ou durante sua formação. Apenas 38,4\% alegaram que foram bem, muito bem ou excelentemente preparados para o mercado de trabalho. 
Pfitscher et al (2007) ao avaliar egressos do curso de Ciências Contábeis da Universidade Federal de Santa Catarina (UFSC) formados entre 1993 e 1995, avaliou que entre as principais dificuldades encontradas pelos egressos encontra-se a exigência de experiência profissional pelos empregadores e um mercado de trabalho concorrido, o que gera a necessidade de encontrar meios alternativos de colocação profissional e criar, por parte do egresso, um diferencial entre os demais concorrentes às vagas de trabalho. A diferenciação entre os concorrentes, conforme citações dos egressos, ocorre, principalmente, pelo aperfeiçoamento profissional, no caso destes egressos ela se deu via o desenvolvimento de cursos de especialização e MBAs.

Rego e Andrade (2010) avaliaram 36,4\% dos 472 egressos do curso de Ciências Contábeis da Universidade Federal do Rio Grande do Norte (UFRN) formados entre 2003 e 2007. A pesquisa avaliou aspectos da escolha da carreira, e observa-se que os principais pontos estavam ligados a aspectos profissionais. Apesar de a escolha ter por base aspectos profissionais, as principais dificuldades encontradas por eles estavam ligadas à baixa remuneração e à falta de valorização profissional, representados por $51,3 \%$ das respostas. Foi encontrado um índice de $8,1 \%$ de não empregabilidade e $29,1 \%$ não atuavam na área contábil. A pesquisa aponta ainda que $82,5 \%$ dos egressos considerava sua formação como ótima ou boa.

Lima et al (2006) fizeram uma avaliação com 114 egressos dos cursos de Administração, Ciências Contábeis e Ciências Econômicas da FEA-RP/USP, de suas cinco primeiras turmas. A pesquisa buscou avaliar fatores como tempo de formação, educação continuada e remuneração salarial. Além disso, também avaliaram a satisfação geral com o curso, e os pontos positivos e negativos de sua formação. Entre os principais pontos negativos da formação indicados pelos egressos, destacou-se o distanciamento do ensino da realidade do mercado, além dos problemas de infraestrutura da faculdade. Essa mesma avaliação de falta de ligação com a prática é encontrada com egressos do curso de Administração da FEA-USP conforme pesquisa apresentada Martins et al (1999). A pesquisa ainda demonstra a excessiva sobreposição de disciplinas, desta forma os egressos indicam a importância de um currículo mais bem dimensionado e flexível.

Machado e Macedo (2013) em pesquisa realizada com egressos do curso de Administração de uma Universidade pública do Paraná, demonstram que os egressos do curso 


\section{EGRESSOS COMO INSTRUMENTO DE AVALIAÇÃO INSTITUCIONAL: UMA ANÁLISE DA \\ FORMAÇÃO E EMPREGABILIDADE DOS EGRESSOS DA FEA-RP/USP \\ DOI: http://dx.doi.org/10.5007/1983-4535.2015v8n1p298}

entendem que o curso deve possuir um corpo docente mais experiente e qualificado, para reduzir a dicotomia teoria versus prática, enfatizando mais a segunda.

A indicação da necessidade de mais conteúdos práticos pode ser encontrada também em estudos de outras áreas, inclusive de cursos tecnológicos, conforme estudos apresentados por Sampaio e Almeida (2013) com egressos do Instituto Federal da Bahia.

Para avaliar a percepção do mercado de trabalho sobre os egressos do curso de Administração de uma IES privada do Rio Grande do Sul, Lima (2006) desenvolveu um estudo para avaliar a satisfação das empresas empregadoras com as competências desenvolvidas no curso, a pesquisa também avaliou o mesmo ponto com os egressos da IES. As pesquisas desenvolvidas em profundidade e por meio de Focus Groups, demonstraram que as competências de Análise Crítica de Informações e Planejamento e Gerenciamento de Projetos foram as competências com melhor desenvolvimento e o Desenvolvimento de equipes como a competência de menor satisfação, tanto para as empresas como para os egressos. As empresas ainda apresentam forte insatisfação com as competências de comunicação interpessoal e intergrupal com os egressos da IES.

No presente artigo, fizemos um levantamento de dados junto aos egressos da FEA-RP, formados entre 1996 e 2012, que corresponde a 17 turmas dos cursos de Administração, Ciências Contábeis e Ciências Econômicas. Dos pontos destacados por Michelan et al (2009), abordaremos os tópicos 1 e 2: descreveremos o perfil do egresso (informações relacionadas à formação acadêmica posterior e aceitação do egresso no mercado), bem como, reportaremos avaliação da IES feita pelo egresso do curso.

\section{METODOLOGIA}

A pesquisa desenvolvida foi um levantamento (survey), que se caracteriza pelo questionamento direto das pessoas cujo comportamento se deseja conhecer. Segundo Martins e Theóphilo (2007), os levantamentos são utilizados quando o pesquisador deseja responder a questões acerca da distribuição de uma variável ou das relações entre características de pessoas ou grupos, da maneira como ocorrem em situações naturais. Os autores expõem ainda que esta é a estratégia mais apropriada para análise de fatos e descrições.

O levantamento efetuado na pesquisa foi desenvolvido por meio de uma web survey, utilizando o software LimeSurvey ${ }^{\circledR}$. De acordo com Umbach (2004) a coleta via internet facilita a obtenção de um maior número de respondentes, além de reduzir custos de pesquisas 


\section{EGRESSOS COMO INSTRUMENTO DE AVALIAÇÃO INSTITUCIONAL: UMA ANÁLISE DA \\ FORMAÇÃO E EMPREGABILIDADE DOS EGRESSOS DA FEA-RP/USP \\ DOI: http://dx.doi.org/10.5007/1983-4535.2015v8n1p298}

tradicionais, como: correio, papel, e telefone, bem como evita o dispêndio de tempo de resposta e no processo de tabulação, além de evitar erros de entrada de dados.

Alguns pontos negativos da web survey também são expostos por Dilmann (2000) como o fato de o respondente não ter acesso eletrônico, ou mesmo de se conseguir os endereços eletrônicos da população almejada. No caso desta pesquisa, estes aspectos foram superados pelo fato de ser um público com perfil de acesso a meios eletrônicos e, também, pelo fato de haver meios para coleta dos contatos da população estudada.

Dilmann (2000) ainda expõe como um possível problema o fato de que a decisão de não responder é susceptível de ser feita mais rapidamente. Para mitigar este problema, foram feitas diversas comunicações aos egressos, principalmente a partir da palavra do diretor da faculdade, sobre a importância do projeto.

Foram enviados e-mails com o convite para responder o questionário de interesse para 1185 alunos dos 1520 alunos formados na FEARP/USP (78\%). Os contatos foram obtidos inicialmente a partir da lista do grupo de discussão dos ex-alunos (googlegroups). Posteriormente, foi feita uma pesquisa nas redes sociais em busca dos alunos não cadastrados no grupo de discussão acima mencionado.

Foram dois meses entre o envio do questionário e o fechamento da coleta. Dos 1185 alunos convidados a responder o questionário, 725 responderam, ou seja, obteve-se resposta de $61,2 \%$ dos alunos convidados e $47,7 \%$ do total dos egressos. A tabela 1, a seguir, apresenta informações da amostra da pesquisa para cada um dos cursos da FEA-RP/USP.

Tabela 1 Tamanho amostral - participação aleatória.

\begin{tabular}{lccc}
\hline Cursos & População & Respondentes & Margem de erro ( $\boldsymbol{\alpha}=\mathbf{9 5 \%})$ \\
\hline Ciências Econômicas & 425 & 151 & $6,4 \%$ \\
\hline Ciências Contábeis & 440 & 226 & $4,5 \%$ \\
\hline Administração & 655 & 348 & $3,6 \%$ \\
\hline Total & 1520 & 725 & $2,6 \%$ \\
\hline
\end{tabular}

Cabe ressaltar que, se a amostra fosse aleatória, ou seja, se todos os indivíduos tivessem a mesma probabilidade de responder ao questionário, a margem de erro da pesquisa (para um intervalo de confiança de 95\%) seria igual ao apresentado na terceira coluna da tabela 1, acima. No entanto, há dois possíveis vieses de seleção nesse processo que devem ser apontados: i) não foram enviados e-mails para todos os formados, mas somente para aqueles com os quais havia contato; ii) nem todos responderam. 


\section{EGRESSOS COMO INSTRUMENTO DE AVALIAÇÃO INSTITUCIONAL: UMA ANÁLISE DA \\ FORMAÇÃO E EMPREGABILIDADE DOS EGRESSOS DA FEA-RP/USP \\ DOI: http://dx.doi.org/10.5007/1983-4535.2015v8n1p298}

Como dito acima, foram enviados convites para quase $80 \%$ dos egressos, ou seja, uma taxa bastante satisfatória. Sendo assim, os pesquisadores entendem que este não seria um grande problema. No entanto, uma parte dos convidados não respondeu a pesquisa. Há sempre uma preocupação de que aqueles que respondem são diferentes dos que não respondem em algum atributo correlacionado com o indicador de resultado que se está interessado, no caso desempenho no mercado de trabalho. Em relação à presente pesquisa, entendemos que de fato esse pode ser um problema, no entanto, não tão grande assim, visto que $61,2 \%$ dos convidados responderam a pesquisa, uma taxa de resposta também alta - mais alta, por exemplo, relativamente aos trabalhos citados na seção anterior deste trabalho.

Na próxima seção são apresentados os resultados obtidos. Os números são mostrados para o total dos egressos, bem como para cada um dos cursos. Embora, os números da pesquisa sejam bastante razoáveis em termos de cobertura e taxa de resposta, é importante que os resultados sejam lidos levando-se em conta as limitações apresentadas anteriormente.

\section{ANÁLISE DOS RESULTADOS}

O questionário aplicado foi dividido em duas partes. Na primeira há uma série de questões fechadas (múltipla escolha) que buscam caracterizar o desempenho dos egressos no mercado de trabalho. Na segunda parte, por sua vez, foi disponibilizado um espaço para que os respondentes pudessem expressar suas impressões sobre sua formação na FEARP/USP. Sendo assim, para facilitar a exposição, são apresentadas análises separadas para cada uma dessas partes.

\subsection{ANÁLISE DAS QUESTÕES FECHADAS: DESEMPENHO NO MERCADO DE TRABALHO}

As primeiras turmas da FEARP/USP ofereciam 40 vagas anuais. A partir de 2000, o curso de Administração passou a oferecer 44 vagas e, em 2004, todos passaram a oferecer 45 vagas. Em 2006, foi criado o curso de Administração no período diurno, com 60 vagas e quatro anos de duração. A tabela 2 apresenta o número de retorno de alunos por turma. Note que esse retorno não está considerando o fato de que nem todos receberam o convite para participar da pesquisa, bem como o fato de que nem todos chegaram à conclusão do curso. A partir desta consideração, observa-se uma taxa média de 32,0\% de retorno sobre os entrantes, sendo a maior taxa observada entre os alunos de Administração $(38,6 \%)$ e a menor entre os de Ciências Econômicas com 22,9\% de retorno. 


\section{EGRESSOS COMO INSTRUMENTO DE AVALIAÇÃO INSTITUCIONAL: UMA ANÁLISE DA \\ FORMAÇÃO E EMPREGABILIDADE DOS EGRESSOS DA FEA-RP/USP \\ DOI: http://dx.doi.org/10.5007/1983-4535.2015v8n1p298}

Tabela 2 Número de retorno de alunos.

\begin{tabular}{|c|c|c|c|c|c|c|c|c|c|c|c|c|}
\hline \multirow{2}{*}{$\begin{array}{l}\text { Data } \\
\text { Início }\end{array}$} & \multicolumn{3}{|c|}{ Ciências Econômicas } & \multicolumn{3}{|c|}{ Ciências Contábeis } & \multicolumn{3}{|c|}{ Administração } & \multicolumn{3}{|c|}{ Total } \\
\hline & Freq. & Entrantes & $\begin{array}{c}\% \\
\text { participação } \\
\end{array}$ & Freq. & Entrantes & $\begin{array}{c}\% \\
\text { participação }\end{array}$ & Freq. & Entrantes & $\begin{array}{c}\% \\
\text { participação }\end{array}$ & Freq. & Entrantes & $\begin{array}{c}\% \\
\text { participação }\end{array}$ \\
\hline 1992 & 6 & 40 & $15,0 \%$ & 7 & 40 & $17,5 \%$ & 11 & 40 & $27,5 \%$ & 24 & 120 & $20,0 \%$ \\
\hline 1993 & 14 & 40 & $35,0 \%$ & 8 & 40 & $20,0 \%$ & 17 & 40 & $42,5 \%$ & 39 & 120 & $32,5 \%$ \\
\hline 1994 & 13 & 40 & $32,5 \%$ & 14 & 40 & $35,0 \%$ & 19 & 40 & $47,5 \%$ & 46 & 120 & $38,3 \%$ \\
\hline 1995 & 4 & 40 & $10,0 \%$ & 19 & 40 & $47,5 \%$ & 14 & 40 & $35,0 \%$ & 37 & 120 & $30,8 \%$ \\
\hline 1996 & 9 & 40 & $22,5 \%$ & 13 & 40 & $32,5 \%$ & 14 & 40 & $35,0 \%$ & 36 & 120 & $30,0 \%$ \\
\hline 1997 & 9 & 40 & $22,5 \%$ & 11 & 40 & $27,5 \%$ & 13 & 40 & $32,5 \%$ & 33 & 120 & $27,5 \%$ \\
\hline 1998 & 11 & 40 & $27,5 \%$ & 17 & 40 & $42,5 \%$ & 14 & 40 & $35,0 \%$ & 42 & 120 & $35,0 \%$ \\
\hline 1999 & 9 & 40 & $22,5 \%$ & 14 & 40 & $35,0 \%$ & 15 & 40 & $37,5 \%$ & 38 & 120 & $31,7 \%$ \\
\hline 2000 & 9 & 40 & $22,5 \%$ & 13 & 40 & $32,5 \%$ & 14 & 44 & $31,8 \%$ & 36 & 124 & $29,0 \%$ \\
\hline 2001 & 9 & 40 & $22,5 \%$ & 13 & 40 & $32,5 \%$ & 23 & 44 & $52,3 \%$ & 45 & 124 & $36,3 \%$ \\
\hline 2002 & 10 & 40 & $25,0 \%$ & 17 & 40 & $42,5 \%$ & 20 & 44 & $45,5 \%$ & 47 & 124 & $37,9 \%$ \\
\hline 2003 & 13 & 40 & $32,5 \%$ & 14 & 40 & $35,0 \%$ & 27 & 44 & $61,4 \%$ & 54 & 124 & $43,5 \%$ \\
\hline 2004 & 11 & 45 & $24,4 \%$ & 17 & 45 & $37,8 \%$ & 22 & 45 & $48,9 \%$ & 50 & 135 & $37,0 \%$ \\
\hline 2005 & 7 & 45 & $15,6 \%$ & 13 & 45 & $28,9 \%$ & 18 & 45 & $40,0 \%$ & 38 & 135 & $28,1 \%$ \\
\hline 2006 & 11 & 45 & $24,4 \%$ & 16 & 45 & $35,6 \%$ & 57 & 105 & $54,3 \%$ & 84 & 195 & $43,1 \%$ \\
\hline 2007 & 6 & 45 & $13,3 \%$ & 10 & 45 & $22,2 \%$ & 37 & 105 & $35,2 \%$ & 53 & 195 & $27,2 \%$ \\
\hline 2008 & 0 & 0 & 0 & 10 & 45 & $22,2 \%$ & 13 & 105 & $12,4 \%$ & 23 & 150 & $15,3 \%$ \\
\hline Total & 151 & 660 & $22,9 \%$ & 226 & 705 & $32,1 \%$ & 348 & 901 & $38,6 \%$ & 725 & 2266 & $32,0 \%$ \\
\hline
\end{tabular}

Para alguns questionamentos serão feitas análises em termos do ano de entrada no curso. Assim, foram feitos agrupamentos de cinco em cinco anos (1992 a 1996, 1997 a 2001, 2002 a 2006), como pode ser observado nos dados expostos na tabela 3.

Tabela 3 Número de formados respondentes por curso.

\begin{tabular}{lcccccccc}
\hline \multirow{2}{*}{ Período } & \multicolumn{2}{c}{ Ciências Econômicas } & \multicolumn{2}{c}{ Ciências Contábeis } & \multicolumn{2}{c}{ Administração } & \multicolumn{2}{c}{ Total } \\
\cline { 2 - 9 } & Freq. & $\%$ & Freq. & $\%$ & Freq. & $\%$ & Freq. & $\%$ \\
\hline 1992 a 1996 & 46 & $31,7 \%$ & 61 & $29,6 \%$ & 75 & $25,2 \%$ & 182 & $28,0 \%$ \\
\hline 1997 a 2001 & 47 & $32,4 \%$ & 68 & $33,0 \%$ & 79 & $26,5 \%$ & 194 & $29,9 \%$ \\
\hline 2002 a 2006 & 52 & $35,9 \%$ & 77 & $37,4 \%$ & 144 & $48,3 \%$ & 273 & $42,1 \%$ \\
\hline Total & 145 & & 206 & & 298 & & 649 \\
\hline
\end{tabular}

Em termos de localização, observa-se que apenas 2,6\% (19 alunos) dos egressos estão localizados no exterior, principalmente na Europa e nos Estados Unidos. Os dados da tabela 4 demonstram que grande parte dos egressos que permaneceram no Brasil estão localizados na região Sudeste, principalmente em São Paulo, que está destacada em separado também na tabela. Os outros estados com destaque são o Rio de Janeiro com 4,0\%, Minas Gerais com $2,8 \%$ e o Distrito Federal com 2,6\%. 


\section{EGRESSOS COMO INSTRUMENTO DE AVALIAÇÃO INSTITUCIONAL: UMA ANÁLISE DA \\ FORMAÇÃO E EMPREGABILIDADE DOS EGRESSOS DA FEA-RP/USP \\ DOI: http://dx.doi.org/10.5007/1983-4535.2015v8n1p298}

Tabela 4 Localização geográfica dos egressos.

\begin{tabular}{lcccc}
\hline Localização & Ciências Econômicas & Ciências Contábeis & Administração & Total \\
\hline Norte & $0,0 \%$ & $0,0 \%$ & $0,0 \%$ & $0,0 \%$ \\
\hline Nordeste & $0,0 \%$ & $0,9 \%$ & $0,9 \%$ & $0,7 \%$ \\
\hline Centro Oeste & $6,6 \%$ & $2,2 \%$ & $3,2 \%$ & $3,6 \%$ \\
\hline Sul & $2,0 \%$ & $1,3 \%$ & $1,4 \%$ & $1,5 \%$ \\
\hline Sudeste & $86,1 \%$ & $94,2 \%$ & $92,2 \%$ & $91,6 \%$ \\
\hline Exterior & $5,3 \%$ & $1,3 \%$ & $2,3 \%$ & $2,6 \%$ \\
\hline SP & $78,1 \%$ & $90,3 \%$ & $83,9 \%$ & $84,7 \%$ \\
\hline
\end{tabular}

Avaliando-se o tempo médio de formação, na tabela 5 observa-se uma grande concentração na faixa de cinco a seis anos de curso, que representa 75,3\% dos alunos avaliados. Como os cursos de Administração e Ciências Contábeis passaram a oferecer cursos com quatro anos só mais recentemente (Administração em 2006 e Ciências Contábeis em 2007), observa-se ainda uma baixa participação desta faixa. Considerando-se que o tempo máximo para a formação em cursos de cinco anos é de nove anos, observa-se que apenas 12 $(1,7 \%)$ deles ultrapassaram este período. Para o curso de Ciências Econômicas, que sempre teve turmas de cinco anos, o tempo médio de formação nesta amostra foi de 5,7 anos.

Tabela 5 Tempo de formação.

\begin{tabular}{ccccccc}
\hline \multirow{2}{*}{ Duração } & \multicolumn{2}{c}{ Ciências Econômicas } & \multicolumn{2}{c}{ Ciências Contábeis } & \multicolumn{2}{c}{ Administração } \\
\cline { 2 - 7 } & Freq. & $\%$ & Freq. & $\%$ & Freq. & $\%$ \\
\hline 4 & 2 & $1,32 \%$ & 22 & $9,73 \%$ & 33 & $9,48 \%$ \\
\hline 5 & 90 & $59,60 \%$ & 107 & $47,35 \%$ & 164 & $47,13 \%$ \\
\hline 6 & 26 & $17,22 \%$ & 53 & $23,45 \%$ & 106 & $30,46 \%$ \\
\hline 7 & 17 & $11,26 \%$ & 22 & $9,73 \%$ & 28 & $8,05 \%$ \\
\hline 8 & 12 & $7,95 \%$ & 12 & $5,31 \%$ & 11 & $3,16 \%$ \\
\hline 9 & 3 & $1,99 \%$ & 4 & $1,77 \%$ & 1 & $0,29 \%$ \\
\hline 10 & 1 & $0,66 \%$ & 4 & $1,77 \%$ & 3 & $0,86 \%$ \\
\hline 12 & 0 & $0 \%$ & 1 & $0,44 \%$ & 1 & $0,29 \%$ \\
\hline 14 & 0 & $0 \%$ & 0 & $0 \%$ & 1 & $0,29 \%$ \\
\hline 15 & 0 & $0 \%$ & 1 & $0,44 \%$ & 0 & $0 \%$ \\
\hline
\end{tabular}

Os egressos foram questionados se tiveram algum outro tipo de formação complementar ao seu curso na FEARP/USP, considerando-se cursos realizados anteriormente, simultaneamente ou posteriormente ao feito na FEA-P/USP. Observa-se pela tabela 6, que em média $14,2 \%$ fizeram outra graduação, e esta taxa foi próxima nos três cursos. Nota-se que as formações complementares e/ou prévias foram principalmente em Direito, para os três cursos; 
em Ciências Contábeis para os formados em Ciências Econômicas e Administração, e em Administração para os formados em Ciências Contábeis.

Tabela 6 Formação complementar.

\begin{tabular}{lcccccccc}
\hline \multirow{2}{*}{ Cursos } & \multicolumn{2}{c}{ Ciências Econômicas } & \multicolumn{2}{c}{ Ciências Contábeis } & \multicolumn{2}{c}{ Administração } & \multicolumn{2}{c}{ Todos } \\
\cline { 2 - 10 } & Freq. & $\%$ & Freq. & $\%$ & Freq. & $\%$ & Freq. & $\%$ \\
\hline Graduação & 20 & $13,2 \%$ & 32 & $14,2 \%$ & 51 & $14,7 \%$ & 103 & $14,2 \%$ \\
\hline Especialização & 53 & $35,1 \%$ & 82 & $36,3 \%$ & 98 & $28,2 \%$ & 233 & $32,1 \%$ \\
\hline Mestrado & 67 & $44,4 \%$ & 49 & $21,7 \%$ & 88 & $25,3 \%$ & 204 & $28,1 \%$ \\
\hline Doutorado & 26 & $17,2 \%$ & 10 & $4,4 \%$ & 29 & $8,3 \%$ & 65 & $9,0 \%$ \\
\hline Alunos & \multicolumn{2}{c}{151} & \multicolumn{2}{c}{226} & & 348 & & 725 \\
\hline
\end{tabular}

Da tabela 6, observa-se ainda que 32,1\% complementaram sua formação com um curso de especialização, sendo que esta taxa média é superior entre egressos formados em Ciências Contábeis e Ciências Econômicas. Em termos de mestrado, a taxa média foi de 28,1\%, com destaque para os formados em Ciências Econômicas: 44\%. As taxas de alunos que desenvolveram programas de mestrado são bem superiores, por exemplo, quando comparado aos números trazidos por Rego e Andrade (2010), Brandalise et al (2013) e Machado e Reis (2013).

Ao analisar os programas de mestrado cursados ou em curso, observa-se que a maior parte fez mestrado na sua própria área de graduação e os principais percentuais encontrados foram:

- Ciências Econômicas - 71,6\% na própria Economia e 6,0\% em Administração;

- Ciências Contábeis - 61,2\% em Contabilidade e 20,4\% em Engenharia de Produção;

- Administração - 77,0\% em Administração e 7,1\% em Engenharia de Produção.

Observa-se também que em média 9,0\% dos egressos estavam fazendo ou tinham feito doutorado, novamente, principalmente entre os egressos de Ciências Econômicas, que teve uma taxa de 17,2\%. Assim como no mestrado observa-se, exceto pelo curso de Ciências Contábeis, que os egressos fizeram doutorado também na sua área de formação da graduação, sendo os principais dados apresentados a seguir:

- Ciências Econômicas - 53,8\% na própria Economia e 11,5\% em Engenharia da Produção;

- Ciências Contábeis - 50,0\% em Administração e 30\% em Contabilidade;

- Administração - 55,1\% em Administração e 20,6\% em Engenharia de Produção. 


\section{EGRESSOS COMO INSTRUMENTO DE AVALIAÇÃO INSTITUCIONAL: UMA ANÁLISE DA \\ FORMAÇÃO E EMPREGABILIDADE DOS EGRESSOS DA FEA-RP/USP \\ DOI: http://dx.doi.org/10.5007/1983-4535.2015v8n1p298}

Observa-se que tanto entre os que fizeram mestrado e doutorado, há uma grande participação da Engenharia de Produção, e isto pode ser explicado pelo fato de que os programas de pós-graduação da FEARP/USP iniciaram-se apenas em 2004 e, na região, as opções de formação mais próximas eram as Engenharias de Produção na cidade de São Carlos, tanto da própria USP como da UFSCar.

Ao analisar a participação no mercado de trabalho, observa-se pela tabela 7 , que $91,8 \%$ dos egressos do curso alegaram estar ocupados, sendo a menor taxa encontrada no curso de Ciências Econômicas. Apenas 59 egressos informaram não estar empregados $(8,2 \%)$ e 36 deles (5,0\%) alegaram estar procurando emprego. Ou seja, 97\% dos egressos da FEARP/USP estão na população economicamente ativa e, dentre esses, 5\% estão desempregados.

Tabela 7 Empregabilidade.

\begin{tabular}{lcccc}
\hline Situação & Ciências Econômicas & Ciências Contábeis & Administração & Todos \\
\hline Empregados & $87,4 \%$ & $93,8 \%$ & $92,5 \%$ & $91,8 \%$ \\
\hline Procurando Emprego & $9,3 \%$ & $2,7 \%$ & $4,6 \%$ & $5,0 \%$ \\
\hline Inativos & $3,3 \%$ & $3,5 \%$ & $2,9 \%$ & $3,2 \%$ \\
\hline
\end{tabular}

Ao se avaliar os egressos empregados, por período de entrada, observa-se na tabela 8 uma relação positiva entre a empregabilidade e o tempo de formação, ou seja, maior empregabilidade quanto maior for o tempo de formação nos cursos de Ciências Contábeis e, principalmente, no de Ciências Econômicas. Já no curso de Administração, observa-se uma relação inversa. No caso da Administração, as taxas dos que procuram emprego e de inatividade são mais altas para os formados há mais tempo, o que explica a relação inversa entre a taxa de ocupação e o tempo de formação.

Tabela 8 Empregabilidade por período de formação.

\begin{tabular}{clcccc}
\hline \multirow{2}{*}{ Período } & \multicolumn{1}{c}{ Situação } & $\begin{array}{c}\text { Ciências } \\
\text { Econômicas }\end{array}$ & $\begin{array}{c}\text { Ciências } \\
\text { Contábeis }\end{array}$ & Administração & Todos \\
\hline & Empregado & $95,7 \%$ & $96,8 \%$ & $93,3 \%$ & $95,1 \%$ \\
\cline { 2 - 6 } 1992 a 1996 & Procurando emprego & $0,0 \%$ & $1,6 \%$ & $2,7 \%$ & $1,6 \%$ \\
\cline { 2 - 6 } & Não procurando & $4,3 \%$ & $1,6 \%$ & $4,0 \%$ & $3,3 \%$ \\
\hline \multirow{2}{*}{1997 a 2001} & Empregado & $87,2 \%$ & $95,6 \%$ & $95,0 \%$ & $93,3 \%$ \\
\cline { 2 - 6 } & Procurando emprego & $4,3 \%$ & $2,9 \%$ & $2,5 \%$ & $3,1 \%$ \\
\cline { 2 - 6 } & Empro procurando & $8,5 \%$ & $1,5 \%$ & $2,5 \%$ & $3,6 \%$ \\
\cline { 2 - 6 } 2002 a 2006 & Procurando emprego & $86,6 \%$ & $90,9 \%$ & $95,8 \%$ & $92,7 \%$ \\
\cline { 2 - 6 } & Não procurando & $9,8 \%$ & $5,2 \%$ & $2,4 \%$ & $2,9 \%$ \\
\hline
\end{tabular}




\section{EGRESSOS COMO INSTRUMENTO DE AVALIAÇÃO INSTITUCIONAL: UMA ANÁLISE DA \\ FORMAÇÃO E EMPREGABILIDADE DOS EGRESSOS DA FEA-RP/USP \\ DOI: http://dx.doi.org/10.5007/1983-4535.2015v8n1p298}

Chamam atenção na tabela 8 , também, as taxas de inatividade relativamente altas para os egressos, das turmas mais novas, de Ciências Econômicas, o que pode ser explicado pela maior participação desses alunos em programas de pós-graduação. Note que dentre os egressos de Ciências Contábeis, as taxas de inatividade também são mais altas para as turmas mais jovens, no entanto, para as turmas de Administração, as taxas de inatividade são mais altas para as turmas mais velhas, talvez indicando que o ingresso na pós-graduação não ocorra imediatamente após a graduação, como parece ser o caso de Ciências Econômicas.

Ao analisar as atividades dos formados, observa-se pela tabela 9 que, em média, 19,1\% dos egressos alegaram atuar fora da sua área de formação, mas a taxa é bem menor no curso de Administração, e são próximas entre os cursos de Ciências Contábeis e Ciências Econômicas. Ou seja, $80 \%$ dos egressos disseram atuar em sua área de formação. Esse número também é bastante superior ao número apresentado em Machado e Reis (2013). De acordo com os cálculos desses autores, com base nos microdados do Censo Demográfico de 2010, dos indivíduos com idade entre 24 e 65 anos, com nível superior completo, ocupados e com rendimentos do trabalho positivos, 33\% tem uma ocupação compatível com sua formação. O maior percentual é entre os formados da área da Saúde (60\%).

Tabela 9 Atuação na área de formação.

\begin{tabular}{lcc}
\hline Atuação na área de formação & Sim & Não \\
\hline Ciências Econômicas & $71,2 \%$ & $28,8 \%$ \\
\hline Ciências Contábeis & $72,2 \%$ & $27,8 \%$ \\
\hline Administração & $90,7 \%$ & $9,3 \%$ \\
\hline Todos & $80,9 \%$ & $19,1 \%$ \\
\hline
\end{tabular}

A tabela 10 aponta que a maior parte dos egressos ocupados está atuando na iniciativa privada, principalmente os da Administração. O segundo grupo de representatividade é dos egressos que atuam no setor público. Com 19,4\%, o grupo é formado principalmente pelos egressos de Ciências Contábeis e Ciências Econômicas. O terceiro maior grupo engloba as atividades autônomas e empreendedoras, representado por 18,0\% dos egressos, com maior participação dos egressos da Administração. O quarto maior grupo se concentra na área de educação com $17,9 \%$ dos egressos, sendo ela na iniciativa pública ou privada. Na educação pública há maior representatividade entre egressos de Ciências Econômicas e na iniciativa privada, os percentuais são próximos para os egressos dos três cursos. Há baixa participação no terceiro setor em todas as áreas de formação. 


\section{EGRESSOS COMO INSTRUMENTO DE AVALIAÇÃO INSTITUCIONAL: UMA ANÁLISE DA \\ FORMAÇÃO E EMPREGABILIDADE DOS EGRESSOS DA FEA-RP/USP \\ DOI: http://dx.doi.org/10.5007/1983-4535.2015v8n1p298}

Note que na tabela 10, a soma das colunas para cada curso, supera $100 \%$. O questionário permitia que os egressos escolhessem mais de uma área de atuação $(10,4 \%$ dos egressos indicaram mais de uma atividade de atuação, e ela é próxima nos três cursos, sendo 9,0\% em Administração, 11,4\% em Ciências Econômicas e 11,8\% em Ciências Contábeis).

Tabela 10 Setor de atuação.

\begin{tabular}{lcccccc}
\hline Curso & $\begin{array}{c}\text { Empresário/ } \\
\text { Autônomo/ } \\
\text { Profissional } \\
\text { liberal }\end{array}$ & $\begin{array}{c}\text { Professor } \\
\text { e/ou } \\
\text { pesquisador } \\
\text { da iniciativa } \\
\text { pública }\end{array}$ & $\begin{array}{c}\text { Professor } \\
\text { e/ou } \\
\text { pesquisador } \\
\text { da iniciativa } \\
\text { privada }\end{array}$ & $\begin{array}{c}\text { Empregado } \\
\text { na iniciativa } \\
\text { pública } \\
\text { (exceto } \\
\text { docência) }\end{array}$ & $\begin{array}{c}\text { Empregado } \\
\text { na iniciativa } \\
\text { privada } \\
\text { (exceto } \\
\text { docência) }\end{array}$ & $\begin{array}{c}\text { Terceiro } \\
\text { Setor }\end{array}$ \\
\hline Ciências Econômicas & $15,2 \%$ & $9,8 \%$ & $12,9 \%$ & $23,5 \%$ & $48,5 \%$ & $1,5 \%$ \\
\hline Ciências Contábeis & $15,1 \%$ & $5,7 \%$ & $12,7 \%$ & $27,4 \%$ & $49,5 \%$ & $1,4 \%$ \\
\hline Administração & $21,1 \%$ & $5,3 \%$ & $10,2 \%$ & $12,4 \%$ & $59,0 \%$ & $0,9 \%$ \\
\hline Todos & $18,0 \%$ & $6,3 \%$ & $11,6 \%$ & $19,4 \%$ & $53,9 \%$ & $1,2 \%$ \\
\hline
\end{tabular}

Os dados anteriores (tabela 10) demonstraram que 19,1\% dos egressos indicaram não estar atuando em sua área de formação. Assim, procurou-se avaliar em qual "tipo de emprego" isso mais ocorre. A tabela 11 demonstra que o "atuar fora da área" é mais comum entre aqueles que estão no setor público $(35,1 \%)$, e é menor entre aqueles que atuam na docência em universidades públicas $(9,3 \%)$.

Tabela 11 Atuação na área $X$ forma de atuação.

\begin{tabular}{lcccccc}
\hline Situação & Empresário & $\begin{array}{c}\text { Professor } \\
\text { /pública }\end{array}$ & $\begin{array}{c}\text { Professor } \\
\text { /privada }\end{array}$ & $\begin{array}{c}\text { Empregado } \\
\text { pública }\end{array}$ & $\begin{array}{c}\text { Empregado } \\
\text { privada }\end{array}$ & $\begin{array}{c}\text { Terceiro } \\
\text { Setor }\end{array}$ \\
\hline Sim & $79,5 \%$ & $90,7 \%$ & $82,1 \%$ & $64,9 \%$ & $86,4 \%$ & $77,8 \%$ \\
\hline Não & $20,5 \%$ & $9,3 \%$ & $17,9 \%$ & $35,1 \%$ & $13,6 \%$ & $22,2 \%$ \\
\hline
\end{tabular}

Questionou-se aos ex-alunos sua renda total mensal (por faixas) e, a partir da renda média e representatividade do intervalo, estimou-se uma renda média do egresso. Os dados da tabela 12 demonstram que ela é próxima entre os egressos da Administração e Ciências Econômicas é, em média, inferior para os egressos de Ciências Contábeis.

Com o objetivo de analisar se o tempo de formação seria fator de impacto para o rendimento dos egressos, buscou-se avaliar a renda média de acordo com o ano de ingresso. Observa-se pela tabela 13 que ela é próxima entre aqueles que ingressaram na FEARP/USP entre 1992 e 2001 e é relativamente menor para os que ingressaram depois de 2002, o que demonstra o impacto do tempo de formação na renda do egresso. 


\section{EGRESSOS COMO INSTRUMENTO DE AVALIAÇÃO INSTITUCIONAL: UMA ANÁLISE DA \\ FORMAÇÃO E EMPREGABILIDADE DOS EGRESSOS DA FEA-RP/USP \\ DOI: http://dx.doi.org/10.5007/1983-4535.2015v8n1p298}

Tabela 12 Renda média mensal por curso.

\begin{tabular}{|c|c|c|c|c|}
\hline Valor & Ciências Econômicas & Ciências Contábeis & Administração & Todos \\
\hline Não declarado & $2,3 \%$ & $1,4 \%$ & $1,6 \%$ & $1,7 \%$ \\
\hline Até $\mathrm{R} \$ 1.500,00$ & $0,8 \%$ & $2,8 \%$ & $1,2 \%$ & $1,7 \%$ \\
\hline De $\mathrm{R} \$ 1.500,01$ a $\mathrm{R} \$ 3.000,00$ & $5,3 \%$ & $7,1 \%$ & $8,1 \%$ & $7,2 \%$ \\
\hline De $\mathrm{R} \$ 3.000,01$ a $\mathrm{R} \$ 5.000,00$ & $16,7 \%$ & $20,8 \%$ & $19,3 \%$ & $19,2 \%$ \\
\hline De $\mathrm{R} \$ 5.000,01$ a $\mathrm{R} \$ 7.500,00$ & $19,7 \%$ & $27,8 \%$ & $21,4 \%$ & $23,1 \%$ \\
\hline De R\$ 7.500,01 a R\$10.000,00 & $18,9 \%$ & $16,5 \%$ & $18,3 \%$ & $17,9 \%$ \\
\hline De R\$ $10.000,01$ a $R \$ 15.000,00$ & $22,0 \%$ & $16,0 \%$ & $12,7 \%$ & $15,6 \%$ \\
\hline De R $\$ 15.000,01$ a $\mathrm{R} \$ 25.000,00$ & $9,8 \%$ & $5,2 \%$ & $11,2 \%$ & $9,0 \%$ \\
\hline De R\$ $25.000,01$ a $\mathrm{R} \$ 50.000,00$ & $2,3 \%$ & $2,4 \%$ & $4,7 \%$ & $3,5 \%$ \\
\hline Acima de $50.000,00$ & $2,3 \%$ & $0,0 \%$ & $1,6 \%$ & $1,2 \%$ \\
\hline Salário Médio & $\mathrm{R} \$ 10.390$ & $\mathrm{R} \$ 8.142$ & $\mathrm{R} \$ 10.263$ & $\mathrm{R} \$ 9.613$ \\
\hline
\end{tabular}

Tabela 13 Rendimento por período de entrada.

\begin{tabular}{|c|c|c|c|}
\hline Valor & 1992 a 1996 & 1997 a 2001 & 2002 a 2006 \\
\hline Não declarado & $2,3 \%$ & $1,7 \%$ & $1,6 \%$ \\
\hline Até $\mathrm{R} \$ 1.500,00$ & $0,0 \%$ & $0,6 \%$ & $2,4 \%$ \\
\hline De $R \$ 1.500,01$ a $R \$ 3.000,00$ & $4,6 \%$ & $1,7 \%$ & $9,9 \%$ \\
\hline De R\$ 3.000,01 a R\$ 5.000,00 & $8,1 \%$ & $7,2 \%$ & $29,2 \%$ \\
\hline De R\$ 5.000,01 a R \$ 7.500,00 & $16,8 \%$ & $19,3 \%$ & $29,6 \%$ \\
\hline De $\mathrm{R} \$ 7.500,01$ a $\mathrm{R} \$ 10.000,00$ & $20,2 \%$ & $21,0 \%$ & $18,2 \%$ \\
\hline De $\mathrm{R} \$ 10.000,01$ a $\mathrm{R} \$ 15.000,00$ & $26,0 \%$ & $24,3 \%$ & $5,9 \%$ \\
\hline De $R \$ 15.000,01$ a $R \$ 25.000,00$ & $11,6 \%$ & $18,8 \%$ & $2,4 \%$ \\
\hline De $\mathrm{R} \$ 25.000,01$ a $\mathrm{R} \$ 50.000,00$ & $8,1 \%$ & $3,9 \%$ & $0,4 \%$ \\
\hline Acima de $\mathrm{R} \$ 50.000,00$ & $2,3 \%$ & $1,7 \%$ & $0,4 \%$ \\
\hline Salário Médio & $\mathrm{R} \$ 13.000$ & $\mathrm{R} \$ 12.453$ & $\mathrm{R} \$ 6.432$ \\
\hline
\end{tabular}

Em relação à renda, foi ainda avaliada se haveria diferença entre as formas de atuação. A tabela 14 demonstra que as rendas menores são encontradas entre aqueles que atuam como docentes na área pública e os que atuam no terceiro setor. Ela é maior entre os que indicam ser empresários/profissionais liberais, empregados do setor privado e docentes de instituições de ensino privado.

Cabe ressaltar que $69,2 \%$ daqueles que atuam como docentes de instituições privadas têm também outra atuação. Ao se analisar a renda média daqueles que atuam somente como docentes no setor privado, o valor se reduz para $\mathrm{R} \$ 8.282$. 


\section{EGRESSOS COMO INSTRUMENTO DE AVALIAÇÃO INSTITUCIONAL: UMA ANÁLISE DA \\ FORMAÇÃO E EMPREGABILIDADE DOS EGRESSOS DA FEA-RP/USP \\ DOI: http://dx.doi.org/10.5007/1983-4535.2015v8n1p298}

Tabela 14 Rendimento por forma de atuação.

\begin{tabular}{|c|c|c|c|c|c|c|}
\hline Valor & Empresário & $\begin{array}{l}\text { Professor em } \\
\text { IES pública }\end{array}$ & $\begin{array}{c}\text { Professor em } \\
\text { IES privada }\end{array}$ & $\begin{array}{l}\text { Empregado } \\
\text { área pública }\end{array}$ & $\begin{array}{l}\text { Empregado } \\
\text { área privada }\end{array}$ & $\begin{array}{l}\text { Terceiro } \\
\text { Setor }\end{array}$ \\
\hline Sem renda/não declarado & $3,1 \%$ & $0,0 \%$ & $0,0 \%$ & $1,5 \%$ & $0,0 \%$ & $0,0 \%$ \\
\hline Até $\mathrm{R} \$ 1.500,00$ & $1,6 \%$ & $11,8 \%$ & $1,3 \%$ & $3,0 \%$ & $0,8 \%$ & $11,1 \%$ \\
\hline De $R \$ 1.500,01$ a $R \$ 3.000,00$ & $5,5 \%$ & $8,8 \%$ & $9,0 \%$ & $11,9 \%$ & $7,5 \%$ & $22,2 \%$ \\
\hline De $\mathrm{R} \$ 3.000,01$ a $\mathrm{R} \$ 5.000,00$ & $20,5 \%$ & $23,5 \%$ & $19,2 \%$ & $26,1 \%$ & $22,1 \%$ & $22,2 \%$ \\
\hline De $R \$ 5.000,01$ a $R \$ 7.500,00$ & $21,3 \%$ & $55,9 \%$ & $19,2 \%$ & $15,7 \%$ & $27,1 \%$ & $11,1 \%$ \\
\hline De $\mathrm{R} \$ 7.500,01$ a $\mathrm{R} \$ 10.000,00$ & $16,5 \%$ & $0,0 \%$ & $15,4 \%$ & $14,2 \%$ & $15,5 \%$ & $22,2 \%$ \\
\hline De $\mathrm{R} \$ 10.000,01$ a $\mathrm{R} \$ 15.000,00$ & $15,7 \%$ & $0,0 \%$ & $19,2 \%$ & $15,7 \%$ & $13,8 \%$ & $11,1 \%$ \\
\hline De R $\$ 15.000,01$ a $R \$ 25.000,00$ & $7,9 \%$ & $0,0 \%$ & $12,8 \%$ & $11,9 \%$ & $8,3 \%$ & $0,0 \%$ \\
\hline De $\mathrm{R} \$ 25.000,01$ a $\mathrm{R} \$ 50.000,00$ & $4,7 \%$ & $0,0 \%$ & $3,8 \%$ & $0,0 \%$ & $3,8 \%$ & $0,0 \%$ \\
\hline Acima de $\mathrm{R} \$ 50.000,00$ & $3,1 \%$ & $0,0 \%$ & $0,0 \%$ & $0,0 \%$ & $1,3 \%$ & $0,0 \%$ \\
\hline Salário Médio & $\mathrm{R} \$ 10.631$ & $\mathrm{R} \$ 4.808$ & $\mathrm{R} \$ 9.948$ & $\mathrm{R} \$ 7.925$ & $\mathrm{R} \$ 9.527$ & $\mathrm{R} \$ 5.583$ \\
\hline
\end{tabular}

Solicitou-se aos egressos que dessem uma nota de 1 a 10 para sua formação na FEARP. Os dados da tabela 15 indicam uma nota média de 8,2, sendo maior entre os egressos de Ciências Contábeis e menor entre os de Ciências Econômicas. A mediana e a moda de todos os cursos foi 8 e houve baixo desvio em todos os cursos. O teste de média (anova) demonstra que não há diferença significativa entre os grupos.

Tabela 15 Nota para formação por curso.

\begin{tabular}{lcccc}
\hline Nota & Ciências Econômicas & Ciências Contábeis & Administração & Todos \\
\hline 1 & $0,0 \%$ & $0,0 \%$ & $0,0 \%$ & $0,0 \%$ \\
\hline 2 & $0,0 \%$ & $0,0 \%$ & $0,0 \%$ & $0,0 \%$ \\
\hline 3 & $0,7 \%$ & $0,0 \%$ & $0,3 \%$ & $0,3 \%$ \\
\hline 4 & $1,3 \%$ & $0,0 \%$ & $0,6 \%$ & $0,6 \%$ \\
\hline 5 & $2,6 \%$ & $1,8 \%$ & $1,1 \%$ & $1,7 \%$ \\
\hline 6 & $5,3 \%$ & $2,7 \%$ & $5,2 \%$ & $4,4 \%$ \\
\hline 7 & $19,2 \%$ & $14,2 \%$ & $18,1 \%$ & $17,1 \%$ \\
\hline 8 & $33,1 \%$ & $36,3 \%$ & $34,8 \%$ & $34,9 \%$ \\
\hline 9 & $27,2 \%$ & $30,5 \%$ & $27,6 \%$ & $28,4 \%$ \\
\hline 10 & $10,6 \%$ & $14,6 \%$ & $12,4 \%$ & $12,7 \%$ \\
\hline Média & 8,0 & 8,3 & 8,2 & 8,2 \\
\hline Desvio & 1,3 & 1,1 & 1,2 & 1,2 \\
\hline Mediana & 8 & 8 & 8 & 8 \\
\hline Moda & 8 & 8 & 8 & 8 \\
\hline
\end{tabular}

\subsection{AVALIAÇÃO DA QUESTÃO ABERTA: PERCEPÇÃO SOBRE A FORMAÇÃO}

Além das variáveis já apresentadas, foi disponibilizado aos egressos um espaço para que eles pudessem colocar percepções sobre sua formação. Em média houve o preenchimento 
por parte de $60,7 \%$ dos egressos, representados principalmente pelos do curso de Administração, conforme demonstra a tabela 16.

Tabela 16 Número de respondentes para a questão aberta.

\begin{tabular}{lccc}
\hline Cursos & Respondentes & Aberta & \% de resposta \\
\hline Ciências Econômicas & 151 & 81 & $53,6 \%$ \\
\hline Ciências Contábeis & 226 & 140 & $61,9 \%$ \\
\hline Administração & 348 & 230 & $66,1 \%$ \\
\hline Total & 725 & 451 & $60,7 \%$ \\
\hline
\end{tabular}

Entre os egressos do curso de Ciências Econômicas que preencheram esta parte do questionário, 50,6\% indicaram a necessidade de ter um curso menos teórico, com conteúdos que atingissem a realidade tanto de empresas de mercado como de órgãos públicos ligados à área econômica.

Como exemplo destas indicações, demonstramos a colocação de um egresso formado pela $12^{\mathrm{a}}$ turma do curso - "O curso precisa ser mais voltado para o mercado e buscar a interação com as empresas. As aulas precisam simular casos reais e buscar visitas nas empresas".

Cabe ressaltar que também apareceram algumas observações, embora em menor volume, para a solicitação de mais conteúdos de caráter teórico, principalmente com enfoque matemático.

Também foram encontradas diversas indicações para que houvesse maior interdisciplinaridade nas disciplinas do curso, bem como com disciplinas dos outros cursos da faculdade. Para isso indicam muito a importância de mais opções de matérias optativas, principalmente em outros cursos.

Também entre os egressos de Ciências Contábeis observou-se a indicação da necessidade de maior proximidade com o mercado, sendo encontrada em 37,1\% das exposições.

Apresenta-se a seguir também um exemplo de citação de um egresso da $15^{\mathrm{a}}$ turma de Ciências Contábeis que reflete a importância da proximidade do mercado no ensino do curso "Tentativa de maior alinhamento entre a teoria e a prática contábil de mercado. A tentativa da FEARP é de formar controllers, entretanto o que se percebe ao entrar no mercado de trabalho é que há certa carência em fundamentos básicos (mais técnicos do que complexos).". 


\section{EGRESSOS COMO INSTRUMENTO DE AVALIAÇÃO INSTITUCIONAL: UMA ANÁLISE DA \\ FORMAÇÃO E EMPREGABILIDADE DOS EGRESSOS DA FEA-RP/USP \\ DOI: http://dx.doi.org/10.5007/1983-4535.2015v8n1p298}

Observaram-se diversas indicações para o aumento de conteúdos específicos, principalmente os ligados às áreas de contabilidade tributária, de contabilidade pública e de controladoria. Entre os alunos mais antigos há ainda a indicação de conteúdos ligados à contabilidade internacional, ponto este já trabalhado na atual grade curricular do curso. Ligando este ponto ao anterior, observam-se também diversas indicações para que haja a obrigatoriedade do estágio na grade curricular, principalmente em substituição ao trabalho de conclusão de curso.

Entre os egressos da Administração, 33,5\% também indicaram a importância de o curso ter maior proximidade com o mercado. Apresenta-se a seguir um exemplo destas indicações pela posição de um egresso da $6^{\mathrm{a}}$ turma - "Maior interação com mercado de trabalho. Contato com empresas, avaliação de casos reais para as matérias aplicadas, etc. $\dot{E}$ importante para os recém formados ter vivenciado o máximo possível as condições reais do mercado. A academia tende a focar demasiadamente na teoria, deixando um pouco de lado a prática do dia a dia."

Outro ponto interessante presente em algumas declarações reforçam a importância do estímulo ao empreendedorismo, e ao conhecimento não só de casos de grandes corporações, o que pode ser observado na seguinte declaração de um egresso da $2^{\mathrm{a}}$ turma - "Que o ensino também tenha foco nas pequenas e médias empresas e, principalmente, que estimule os alunos empreendedores e a abertura de suas empresas."

Em relação a conteúdos do curso, há diversas opiniões sobre a falta ou excesso de determinados conteúdos, principalmente os de formação geral em métodos quantitativos e disciplinas de conteúdos humanísticos.

Entre os egressos de Administração também foram encontradas abordagens da importância da internacionalização do ensino, principalmente expondo a relevância do incentivo aos intercâmbios, e da inserção de disciplinas em inglês no curso.

Outro ponto de destaque observado pelos egressos de Administração foi a indicação da importância de serem criados mecanismos que permitam apoiar o aluno para seu início de carreira, principalmente com ações de apoio ao processo de escolha de possibilidades de atuação. Cita-se como exemplo a exposição feita por um egresso da $10^{\mathrm{a}}$ turma " $A$ saída ao término do curso é essencial. Há uma necessidade grande de placement dos alunos, auxílio em decisões de carreira ou até trazer empresas para a FEARP (tipo feiras, fóruns de emprego, etc)." 


\section{EGRESSOS COMO INSTRUMENTO DE AVALIAÇÃO INSTITUCIONAL: UMA ANÁLISE DA \\ FORMAÇÃO E EMPREGABILIDADE DOS EGRESSOS DA FEA-RP/USP \\ DOI: http://dx.doi.org/10.5007/1983-4535.2015v8n1p298}

Um ponto importante a ser destacado na análise da questão aberta é de que apesar de haver diversas colocações em relação a alguns pontos da formação, principalmente sobre o afastamento do mercado, elas foram expostas em um tom de sugestão de melhoria dos conteúdos. Ou seja, não foram feitas críticas à formação dada pela faculdade, e isto pode ser ratificado pela nota média dada aos cursos que foi de 8,2 .

\section{CONSIDERAÇÕES FINAIS}

O objetivo desse texto foi apresentar a análise dos dados de pesquisa realizada junto aos egressos da FEARP/USP. Nesta pesquisa, realizada no primeiro semestre de 2012, buscou-se conhecer as características de inserção no mercado de trabalho desses egressos. Em função, principalmente, do caráter voluntário da pesquisa, os resultados devem sempre ser lidos com essa cautela.

De acordo com os resultados obtidos, parte considerável dos egressos teve algum tipo de formação complementar seguindo a graduação. Observa-se que 32,1\% dos egressos fizeram algum curso de especialização; em termos de mestrado, a taxa média foi de $28,1 \%$, com destaque para os formados em Ciências Econômicas: 44\%.

A taxa de empregabilidade entre os egressos é superior a 95\%, com taxa de desemprego de 5\%, semelhante às estimativas atuais do mercado de trabalho (segundo a Pesquisa Mensal de Emprego do IBGE, a taxa de desocupação foi de 5,6\% em julho de 2013); com relação à área de atuação, $80 \%$ disseram atuar na sua área de formação, com destaque para os egressos da Administração (90\%). Os dados encontrados são também superiores aos identificados nos trabalhos prévios analisados.

Com relação à ocupação, a pesquisa apontou que a maior parte dos egressos está atuando na iniciativa privada (54\%), com renda mensal média próxima a $\mathrm{R} \$ 10.000$, sendo esta positivamente correlacionada com o ano de ingresso na FEARP/USP.

$\mathrm{Na}$ análise da exposição livre dos egressos, um ponto abordado pelos egressos dos três cursos foi a questão do afastamento entre os conteúdos dados em aula e a realidade do mercado, mas conforme já observado na revisão de literatura esta forte contestação da necessidade de conteúdos mais próximos à realidade de mercado não é exclusiva desta IES.

Os dados aqui levantados são uma primeira tentativa de conhecer o desempenho dos egressos da FEARP/USP no mercado de trabalho. Os resultados foram bastante satisfatórios, 
indicando uma inserção de qualidade: a maior parte dos egressos atua em sua área de formação e obtém salários compatíveis com a média de mercado.

\section{BIBLIOGRAFIA}

ABREU JUNIOR, N. Sistema(s) de avaliação da educação superior brasileira. Cadernos Cedes. v.29, n.78, 2009

BRANDALISE, L.T.; ROJO, C.A.; KASPER, D.; SOUZA, A.F. O papel social da universidade no preparo profissional: uma pesquisa junto aos egressos de administração da Unioeste - Cascavel. Revista de Gestão Universitária da América Latina. v.6, n.1, 2013

COELHO, M.S.C.; OLIVEIRA, N.C.M. Os egressos no processo de avaliação. Revista eCurriculum, v.8, n.2, 2012

DILLMAN, D. A. Mail and Internet surveys:The tailored design method. New York: John

Wiley \& Sons, Inc, 2000.

LIMA, C.B.; SCHOUTEN, M.V.M.; MARTINELLI, D.P. Perfil profissiográfico de egresso das cinco primeiras turmas dos cursos de graduação de uma instituição de ensino superior. Revista de Gestão USP. v. 13, n. especial, p. 1-18, 2006 .

LIMA, S.B.P. Avaliação da satisfação das empresas empregadoras e dos egressos com as competências desenvolvidas no curso de administração da instituição educacional superior - um estudo de caso. 2006. Dissertação (Mestrado em Administração) - Programa de Pós-Graduação em Administração e Negócios, Pontifícia Universidade Católica do Rio Grande do Sul, 2006

LOUSADA, A.C. Z.; MARTINS, G.A. Egressos como fonte de informação à gestão dos cursos de Ciências Contábeis. Revista Contabilidade e Finanças. v.16, n. 37, 2005

MACHADO, R.; MACEDO, J. Qualidade do ensino superior em administração: Avaliação dos Egressos de uma Universidade Pública na Região do PR. Revista Espacios. v.34 n.3, 2013

MACHADO, D.; REIS, M. C. Uma análise dos rendimentos do trabalho entre indivíduos com ensino superior por área de formação. In: Anais do $41^{\circ}$ Encontro da ANPEC. Foz do Iguaçu, 2013.

MARTINS, G.A.; CARVALHO, P.S.; RIBEIRO NETO, R.M. Ex-alunos do curso de graduação em administração da FEA-USP. In: In: IV Seminários em Administração, 1999, São Paulo. Anais...São Paulo: PPGA/FEA/USP, 1999.

MARTINS, G. A.; THEÓPHILO, C. R. Metodologia da investigação científica para ciências sociais aplicadas. São Paulo: Atlas, 2009.

MEIRA, M.D.D.; KURCGANT, P. Avaliação de cursos graduação segundo egressos. Revista da Escola de Enfermagem da USP. v.43, n.2, 2009 
MEIRELES, F.R.S.;FREITAS, A.R.P.; ABREU, M.C.S.; REBOUÇAS, S.M.D.P. Uma avaliação dos conhecimentos necessários, adquiridos e utilizados pelos egressos do curso de administração. Revista de Gestão Universitária da América Latina. v.6, n.3, 2013

MICHELAN, S.L.; HARGER, C.A.; EHRHARDT, G.; MORÉ, R.P.O. Gestão de egressos em instituições de ensino superior: possibilidades e pontencialidades. In: IX Colóquio Internacional sobre gestão universitária na América do Sul.Florianópolis, 2009

PFITSCHER, E.D.; VICENTE, E.F.R.;COSTA,F.I.B.; VIEIRA, E.M.F.; LIMONGI,B.; ALBERTON,L. Egressos como Fonte de Informação: O Perfil dos Acadêmicos do Curso de Ciências Contábeis e sua Atuação no Mercado de Trabalho em Comparação com os Cursos de Serviço Social e Direito. In: Congreso Transatlántico de Contabilidad, Auditoria, Control de Gestión y X Congreso del Instituto Internacional de Costos, 2007, Lyon: Universidad Jean Moulin, 2007

PUGES, L.M. O perfil profissional de egressos dos cursos de Ciências Contábeis no Rio Grande do Sul. In: $18^{\circ}$ Congresso Brasileiro de Contabilidade, Gramado, 2008

REGO, T.F.; ANDRADE, E.R.G. Perfil e campo de atuação profissional dos egressos do curso de ciências contábeis da UFRN. Revista Ambiente Contábil. v.2, n.2, 2010

RIBEIRO, J.L.S.R. Avaliação das universidades brasileiras as possibilidades de avaliar e as dificuldades de ser avaliado. Revista da Avaliação da Educação Superior. v.16, n.1, 2011

SAMPAIO, R.L.; ALMEIDA, A.R.S. Teoria e prática na formação técnica: um estudo de caso com os egressos do Instituto Federal da Bahia. Revista e-Curriculum, v.11, n.2, 2013 SOBRINHO, J.D. Avaliação e transformações da educação superior brasileira (1995-2009): do Provão ao SINAES. Revista da Avaliação da Educação Superior. v.15, n.1, 2010

STADTLOBER, C.S. Qualidade do ensino superior no curso de administração: a avaliação dos egressos. 2010. Tese (Doutorado em Educação) - Programa de Pós-Graduação de Educação, Pontifícia Universidade Católica do Rio Grande do Sul, 2010

UMBACH, P.D. Web surveys: Best practices. New Directions for Institutional Research. v.2004, n.121, 2004. 